\title{
Study of management of postpartum hemorrhage and its complications
}

\author{
Yogesh Thawal, Dipak S. Kolate*, Meenal M. Patvekar, \\ Shikha Jindal, Hemant Deshpande, Amrita Bhola
}

Department of Obstetrics and Gynecology, Dr. D Y Patil Vidyapeeth, Pimpri, Pune, Maharashtra, India

Received: 02 March 2019

Accepted: 30 March 2019

\section{*Correspondence:}

Dr. Dipak S. Kolate,

E-mail: drdkpune@gmail.com

Copyright: (C) the author(s), publisher and licensee Medip Academy. This is an open-access article distributed under the terms of the Creative Commons Attribution Non-Commercial License, which permits unrestricted non-commercial use, distribution, and reproduction in any medium, provided the original work is properly cited.

\begin{abstract}
Background: Postpartum hemorrhage (PPH) is globally one of the most common causes of maternal death, especially in developing country like India. Pregnancy and childbirth involve significant health risks, even to women with no preexisting health problem. The objective of this study was to analyze the role of various interventions in the management of PPH and its complications.

Methods: This prospective observational study was conducted in the department of obstetrics and gynecology of Department of Obstetrics and Gynecology, Dr. D Y Patil Medical college, Pimpri, Pune, Maharashtra, India. A total number of 80 cases of postpartum hemorrhage that fulfilled the selection criteria were included. Data collected and analyzed in PPH patients with medical and surgical management.

Results: In present study, most of cases were multigravida (60\%) and more than 50 percent of patients required blood and blood products. In present study, most of the postpartum bleeding or postpartum hemorrhage (PPH) cases managed by medical methods. Uterotonic drugs (42.5\%) This was possible due to early identification and timely intervention.

Conclusions: Active management of third stage of labour is recommended in all cases. Seventy percent cases were managed by medical methods while rest of the cases required surgical management. Among the medical management uterotonic drugs and bimanual uterine compression was used while among the surgical methods repair of cervical and vaginal laceration was mostly required.
\end{abstract}

Keywords: Hysterectomy, Internal illiac artery ligation, Oxytocin, PPH, Uterotonic

\section{INTRODUCTION}

Postpartum haemorrhage is defined as more than $500 \mathrm{ml}$ blood loss within 24 hours following vaginal delivery and $1000 \mathrm{ml}$ following caesarean delivery. ${ }^{1,2}$ Every year about 14 million women around the world suffer from PPH. ${ }^{3}$ The risk of maternal mortality from haemorrhage is 100 per 100000 live births deliveries in developing countries. Most deaths (about 99\%) from PPH occur in low- and middle-income countries compared with only $1 \%$ in industrialized nations. ${ }^{4}$ With 56,000 maternal deaths,
India accounted for $19 \%$ of global burden of maternal deaths in 2010, though it has only $16 \%$ of global population. ${ }^{5}$

PPH is a frequent complication of delivery and its reported incidence in India is $2 \%-4 \%$ after vaginal delivery and $6 \%$ after cesarean section with uterine atony being the most common cause $(50 \%){ }^{6}$ In case of PPH, uterine atony stands as the most common cause. Other causes include injury to genital tract, prolonged labour, retained placenta, foetal macrosomy, multiple 
pregnancies, polyhydramnios, uterine myoma, placenta praevia, grand multiparity, uterine infection and trauma. ${ }^{2}$

A number of drugs and various surgical techniques are used for prevention and control of PPH. But prevention is always better than cure and this study is focused on it.

Active management of third stage of labour is implemented as a package including uterotonic therapy with delivery of the anterior shoulder, early cord clamping and placental delivery by controlled cord traction following signs of placental separation.? Oxytocin is the most commonly used uterotonic agent for the prevention of $\mathrm{PPH}$.

Other uterotonic agents like methylergometrine (ergot alkaloids) and prostaglandins have been studied and have been shown to reduce PPH. ${ }^{8}$

The two main aspects of postpartum haemorrhage are resuscitation and identification and management of underlying cause. Interventions like application of compression sutures, internal iliac artery ligation, uterine artery embolization and hysterectomy are other life saving measures. ${ }^{9}$

The objective of this research study is to optimize different management protocols in cases of postpartum haemorrhage and it's minor and major complications. The aims and objectives of this study were to overview different management protocols of postpartum haemorrhage (PPH), to study minor and major complications due to postpartum haemorrhage ( $\mathrm{PPH})$.

\section{METHODS}

A cross-sectional study was conducted from July 2016 to June 2018 on all cases of postpartum hemorrhage admitted in Department of Obstetrics and Gynecology of Padmashree Dr. D. Y. Patil Medical College, Hospital and Research Centre, Pimpri, Pune.

A predesigned semi-structured questionnaire was prepared based on the review of literature on post-partum hemorrhage.

The questionnaire included the information regarding age, gestational age, parity, history of abortions, comorbidity and addiction. It also included information regarding amount of blood loss, risk factors, mode of delivery, birthweight of child, causes of PPH, blood transfusion, management of PPH and maternal morbidity.

\section{Inclusion criteria}

- Patients with estimated blood loss more than $500 \mathrm{ml}$ after vaginal delivery and more than $1000 \mathrm{ml}$ after caesarean delivery

- Patients with excessive bleeding that makes the patient symptomatic (e.g. lightheadedness, vertigo, syncope) and/or results in signs of hypovolemia (e.g., hypotension, tachycardia or oliguria) and/or 10 percentage decline in postpartum hemoglobin concentration from prepartum levels.

\section{Exclusion criteria}

- Patient unwilling to participate in the study

- Women who are too sick to give consent or to be interviewed.

The management of the patients will be as per decision of the consultant in charge of the patient.

All patients will receive active management of third stage of labor. Patients with uterine atony with additional uterotonics will be noted.

Patients with traumatic postpartum haemorrhage will be treated with repair of trauma. Patients with retained placenta will be treated by doing manual removal of placenta under general anaesthesia. Patients with disorder of coagulation will be treated with transfusing with blood and blood products.

Patients with postpartum haemorrhage will be analysed for presence of risk factors and patients will be followed up in ward for maternal morbidity with sequelae such as shock, renal failure, acute respiratory distress syndrome, coagulopathy and Sheehan's syndrome.

Incidence of postpartum haemorrhage will be calculated for study period. In case of severe haemorrhage, cases will be given the usual management of postpartum haemorrhage and the supplemental treatment will be noted.

\section{Statistical analysis}

Data recorded and analysis done using software.

\section{RESULTS}

The management of the patients will be as per decision of the consultant in charge of the patient. All patients will receive active management of third stage of labor. Patients with uterine atony with additional uterotonics will be noted.

Patients with traumatic postpartum haemorrhage will be treated with repair of trauma.

Patients with retained placenta will be treated by doing manual removal of placenta under general anaesthesia. Patients with disorder of coagulation will be treated with transfusing with blood and blood products.

Patients with postpartum haemorrhage will be analysed for presence of risk factors and patients will be followed up in ward for maternal morbidity with sequelae such as 
shock, renal failure, acute respiratory distress syndrome, coagulopathy and Sheehan's syndrome.

Incidence of postpartum haemorrhage will be calculated for study period. In case of severe haemorrhage, cases will be given the usual management of postpartum haemorrhage and the supplemental treatment will be noted.

Data recorded and analysis done using software. Mean age 26.4 \pm 7.4 years (Table 1).

Table 1: Age distribution of cases.

\begin{tabular}{|lll|}
\hline Age (in years) & Frequency & Percent \\
\hline $18-24$ & 25 & 31.2 \\
\hline $25-28$ & 35 & 43.8 \\
\hline $29-35$ & 12 & 15.0 \\
\hline 35 and above & 8 & 10.0 \\
\hline Total & 80.0 & 100.0 \\
\hline
\end{tabular}

Most of the cases were of multigravida as per findings (Table 2).

Table 2: Distribution of cases according to parity.

\begin{tabular}{|lll|}
\hline Number & Frequency & Percent \\
\hline Primigravida & 32 & 40.0 \\
\hline Multigravida & 48 & 60.0 \\
\hline Total & 80 & 100.0 \\
\hline
\end{tabular}

It was observed that 37 (46.2) participants had blood loss between 1000-1499ml (Table 3).

Table 3: Distribution of cases according to blood loss.

\begin{tabular}{|lll|}
\hline Blood loss $(\mathrm{ml})$ & Frequency & Percent \\
\hline $500-999$ & 28 & 35.0 \\
\hline $1000-1499$ & 37 & 46.2 \\
\hline $1500-1999$ & 12 & 15.0 \\
\hline $2000-2499$ & 3 & 3.8 \\
\hline Total & 80 & 100.0 \\
\hline
\end{tabular}

According to results (Table 4), more than 50 percent of patients required blood and blood products. In present study, most of the PPH cases managed by medical methods.

Table 4: Distribution of cases according to blood transfusion.

\begin{tabular}{|lll|}
\hline Blood transfusion & Frequency & Percent \\
\hline Blood transfusion & 44 & 55.0 \\
\hline Platelet transfusion & 6 & 7.5 \\
\hline FFP transfusion & 2 & 5.0 \\
\hline
\end{tabular}

This was possible due to early identification and timely intervention in our institute (Table 5). It was observed 38
(62.5) cases had febrile morbidity followed by anaemia. Most sever morbidity caused due to sepsis.

\section{Table 5: Distribution of cases according to management of PPH.}

\begin{tabular}{|lll|}
\hline Management & Frequency & Percent \\
\hline Medical management & & \\
\hline Uterotonic drugs & 56 & 70.0 \\
\hline Bimanual uterine & 34 & 42.5 \\
\hline Compression & 22 & 27.5 \\
\hline Surgical management & & \\
\hline $\begin{array}{l}\text { Repair of cervical and } \\
\text { vaginal laceration }\end{array}$ & 12 & 15.0 \\
\hline Removal of retained placenta & 24 & 30.0 \\
\hline Uterine artery ligation & 4 & 5.0 \\
\hline Internal illiac & 4 & 5.0 \\
\hline Artery ligation & 2 & 2.5 \\
\hline Hysterectomy & 2 & 2.5 \\
\hline Total & 80 & 100.0 \\
\hline
\end{tabular}

Such increased morbidity was responsible for prolong stay, use of broad-spectrum antibiotics and ultimately increased socioeconomic burden (Table 6).

\section{Table 6: Distribution of cases according to} maternal morbidity.

\begin{tabular}{|lll|}
\hline Maternal morbidity & Frequency & Percent \\
\hline Fever & 38 & 62.5 \\
\hline Anemia & 12 & 15.0 \\
\hline CCF & 2 & 5.0 \\
\hline Sepsis & 2 & 2.5 \\
\hline No morbidity & 45 & 56.2 \\
\hline Total & 80 & 100.0 \\
\hline
\end{tabular}

\section{DISCUSSION}

PPH remains a major cause of both maternal mortality and morbidity worldwide more so in developing countries with an estimated mortality rate of 140,000 per year or one maternal death every four minutes. PPH occur in $5 \%$ of all deliveries, majorities of death occur within four hours of delivery indicating that it is a consequence of third stage of labour. ${ }^{11}$ The unacceptably high maternal death of 540 per 100,000 live births in India in last few decades remain a major challenge.

Healthy pregnant women can typically tolerate 500 to $1,000 \mathrm{~mL}$ of blood loss without having signs or symptoms. Tachycardia may be the earliest sign of postpartum hemorrhage. Other signs such as hypotension, orthostasis, nausea, dyspnea, oliguria, and chest pain may indicate hypovolemia from significant hemorrhage. If excess bleeding is diagnosed, the four T's mnemonic (uterine atony (tone); laceration, hematoma, inversion, rupture (trauma); retained tissue or invasive placenta (tissue); and coagulopathy (thrombin) can be used to 
identify specific causes. Regardless of the cause of bleeding, physicians should immediately summon additional personnel and begin appropriate emergency hemorrhage protocols. ${ }^{11}$

Hysterectomy is the traditional treatment for cases of refractory $\mathrm{PPH}$, when all other methods to arrest bleeding fails. Advances in interventional radiology and surgical techniques have provided safe and effective alternatives to hysterectomy in many cases. ${ }^{10}$

In the present study, it was observed that 35 (43.8) participants were between 25-28 years of age followed by 25 (31.2) participants between 18-24 years of age.

Similar finding reported by Ononge $\mathrm{S}$ et al, and HalleEkane GE et al. ${ }^{10,11}$ In the study conducted by Ononge $\mathrm{S}$ et al, it was observed that 31 (29.0) cases were of primigravida and 76 (71.0) cases were of multigravida. Similar findings reported in present study. ${ }^{10}$

In the present study, it was observed that 28 (35.0) participants had blood loss between $500-999 \mathrm{ml}, 37$ (46.2) participants had blood loss between 1000-1499 ml, 12 (15.0) participants had blood loss between 1500-1999 $\mathrm{ml}$ and 3 (3.8) participants had blood loss between 2000$2499 \mathrm{ml}$. The parallel things observed by Ngwenya S et al, and study by Nakagawa K et al. ${ }^{12,13}$

In the present study, it was observed that 62 (77.5) cases had uterine atony, 12 (15.0) cases had perineal trauma, 4 (5.0) cases had retained placenta and 2 (2.5) cases had bleeding disorder. Most of the studies reported same findings. ${ }^{11,12,14}$

In present study, it was observed 56 (70.0) cases had medical management and 24 (30.0) cases had surgical management. Among the medical management, 34 (42.5) cases had used uterotonic drugs used and 22 (27.5) cases had bimanual uterine compression.

Among the Surgical management, 12 (15.0) cases had repair of cervical and vaginal laceration, 4 (5.0) cases had removal of retained placenta, 4 (5.0) cases had uterine artery ligation, 4 (5.0) cases had internal illiac artery ligation and 2 (2.5) cases had hysterectomy done. ${ }^{14,15}$ In the study conducted by Kodla CS et al, 4 (3.74) cases had internal illiac artery ligation, 9 (7.8) cases had uterine artery ligation and 23 (25.56) cases had hysterectomy done. $^{14}$

Sheldon W et al, observed similar medical and surgical interventions. ${ }^{15}$ Authors observed that 44 (55.0) cases had blood transfusion, 6 (7.5) cases had platelet transfusion and 2 (5.0) cases had FFP transfusion. Our findings are comparable with other studies. ${ }^{14,15}$ In the present study it was observed 38 (62.5) cases had fever, 12 (15.0) cases had anemia, 2 (5.0) cases had CCF and 2 (2.5) cases had Sepsis. Similar maternal morbidity reported in study conducted by Kodla CS et al. ${ }^{14}$

\section{CONCLUSION}

Uterine atony followed perineal trauma were the most common causes of PPH.

Haemorrhage is the leading cause of the admissions to the intensive care unit and the most preventable cause of the maternal mortality. There is not a universally agreed management strategy for PPH. Seventy percent cases were managed by medical methods while rest of the cases required surgical management. Among the medical management uterotonic drugs and bimanual uterine compression was used while among the surgical methods repair of cervical and vaginal laceration, removal of retained placenta, uterine artery ligation. Only two cases required internal illiac artery ligation and hysterectomy.

Funding: No funding sources

Conflict of interest: None declared

Ethical approval: The study was approved by the Institutional Ethics Committee

\section{REFERENCES}

1. Rath WH. Postpartum hemorrhage update on problems of definitions and diagnosis. Acta Obstet Gynecol Scandinav. 2011;90(5):421-8.

2. Rani PR, Begum J. Recent advances in the management of major postpartum haemorrhage-a Review J Clinic Diagnostic Res.2017;11(2): QE01.

3. Willson JR. Prevention and treatment of postpartum hemorrhage. Surgical Clinic North Am. 1954;34(6):1591-9.

4. Haeri S, Dildy III GA. Maternal mortality from hemorrhage. Seminars Perinatol. 2012; 36(1): 48-55.

5. World health organization, UNICEF, UNFPA, The World Bank (2012). Trends in maternal mortality: 1990 to 2010. WHO, UNICEF, UNFPA. Accessed at:https://www.who.int/reproductivehealth/publicatio ns/monitoring/9789241503631/en/.

6. Amy JJ. Severe postpartum haemorrhage: a rational approach. National Med J India. 1998;11(2):86-8.

7. Cunningham FG, Gant NF, Leveno KJ, eds. Williams Obstetrics 21st ed. USA, McGraw Hill. 2001:619-70.

8. Su LL, Chong YS, Samuel M. Oxytocin agonists for preventing postpartum haemorrhage. Cochrane Database Systematic Reviews. 2007(3).

9. Reynders FC, Senten L, Tjalma W, Jacquemyn Y. Postpartum hemorrhage: practical approach to a lifethreatening complication. Clin Exp Obstet Gynecol. 2006;33(2):81-4.

10. Ononge S, Mirembe F, Wandabwa J, Campbell OM. Incidence and risk factors for postpartum hemorrhage in Uganda. Reprod Health. 2016;13(1):38.

11. Halle-Ekane GE, Emade FK, Bechem NN, Palle JN, Fongaing D, Essome $\mathrm{H}$, et al. Prevalence and Risk Factors of Primary Postpartum Hemorrhage after Vaginal Deliveries in the Bonassama District 
Hospital, Cameroon. Int $\mathbf{J}$ Tropical Dis Health. 2016;13(2):1-2.

12. Ngwenya S. Postpartum hemorrhage: incidence, risk factors, and outcomes in a low-resource setting. Int $\mathrm{J}$ Women's Health. 2016;8:647.

13. Nakagawa $K$, Yamada $T$, Cho K. Independent risk factors for postpartum haemorrhage. Crit Care Obstet Gynecol. 2016;2:10.

14. Kodla CS. A study of prevalence, causes, risk factors and outcome of severe obstetrics haemorrhage. J Sci Innovative Res. 2015;4(2):83-7.

15. Sheldon W, Blum J, Vogel JP, Souza JP, Gülmezoglu AM, Winikoff B, WHO multicountry survey on maternal and newborn health research network. Postpartum haemorrhage management, risks, and maternal outcomes: findings from the World health organization multicountry survey on maternal and newborn health. BJOG: Int J Obstet Gynaecol. 2014;121:5-13.

Cite this article as: Thawal V, Kolate DS, Patvekar MM, Jindal S, Deshpande H, Bhola A. Study of management of postpartum haemorrahage and its complications. Int J Reprod Contracept Obstet Gynecol 2019;8:1790-4. 